\title{
Implicit Demonstrative Reference With Reference to English Arabic Translation: The Case of Harry Potter and the Prisoner of Azkaban Novel
}

\author{
Arwa N. T. Alhinnawi ${ }^{1} \&$ Basem Shu. Al-Zughoul ${ }^{1}$ \\ ${ }^{1}$ Zarqa University College, Al-Balqa Applied University, Zarqa, Jordan \\ Correspondence: Arwa N. T. Alhinnawi, Zarqa University College, Al-Balqa Applied University, Zarqa, Jordan.
}

Received: April 19, 2019 Accepted: June 1, 2019 Online Published: June 3, 2019

doi: $10.5539 /$ elt.v12n7p46 URL: https://doi.org/10.5539/elt.v12n7p46

\begin{abstract}
The present study aims at exploring the way in which English implicit demonstrative reference is rendered into Arabic through analyzing a number of sentences in the novel "Harry Potter and the Prisoner of Azkaban," written by J. K. Rowling (2010), and its Arabic translated version by Ahmad Hassan Mohammed (2010). The scrutiny of the English implicit demonstrative reference shows that it can be translated into Arabic, whether implicitly or explicitly. This procedure is determined by the entailment of the demonstrative reference, whether it is clear and comprehensible, or unclear and incomprehensible. Also, the study has revealed that literal translation and formal equivalence present themselves as valid options in translating the English implicit demonstrative reference into Arabic. Recommendations of the study are stated at the end of the present research paper.
\end{abstract}

Keywords: implicit meaning, demonstrative reference, formal equivalence, literal translation

\section{Introduction}

\subsection{Background of the Study}

Sometimes the meaning of the text might not be stated overtly in the original text. In this respect, Larson (1984) states that the "implicit meaning is a meaning that is not shown but it is the part of the conversation or intention to convey to the speaker" (p. 36).

Another thing to mention is that the meaning that conveys the implicit information has the implied message. This message is a part of the whole meaning. Therefore, the translation of implicit meaning may lead to misinterpretation of the target language because of the linguistic and cultural differences between the source and target languages. An example on the use of the demonstrative reference which might constitute a difficulty for translators is the following sentence with two responses.

They broke a Chinese vase.

a. That was valuable.

b. That was careless.

In the first response the word "that" refers to the vase while in the second response, it refers to the whole incidence of breaking the vase.

It is worth mentioning that a good translation is a translation which conveys messages, thoughts, ideas and concepts from the source language thoroughly and correctly.

In this respect, Larson (1998) states that effective translation transfers the meaning (semantics) of the source language to the target language by changing the form (lexicon and grammar) of the source language into the form of the target language. In other words, the original meaning must stay constant; the form it takes in the target language does not matter. Besides, the target language should be in its natural forms and appropriately communicative in the sense that it can convey all the aspects of meaning which are readily understandable to the readers.

\subsection{Statement of the Problem}

The demonstrative reference is sometimes a source of difficulty for translators due to the fact that English and 
Arabic belong to two different language families and two different cultural backgrounds.

\subsection{Hypotheses of the Study}

1) It is hypothesized that the implicit demonstrative reference in English is rendered implicitly into Arabic.

2) Literal translation and formal equivalence present themselves as valid options in translating the English implicit demonstrative reference into Arabic.

\section{Review of the Related Literature}

\subsection{Implicit Meaning}

Implicit meaning is the meaning which is not stated overtly in the original text. In this respect, Larson (1984) states that the "implicit meaning is a meaning that is not shown but it is the part of the conversation or intention to convey the speaker" (p. 36).

From this starting point, to understand and achieve the correct message of a source language text, the terms of reading the lines and reading between the lines should be maintained. As stated above, we conclude that implicit meaning is the idea that appears on a text that is not explicitly uttered but it is still the part of what the texts intends to.

\subsection{Demonstrative Reference}

Demonstrative reference is essentially a form of verbal pointing in which the speaker identifies the referent event by locating it on a scale of proximity. In other words, the demonstrative reference refers to a set of deictic expressions, including demonstratives such as this, that, these and those. These expressions refer to objects or entities by describing them in terms of some relative aspect of the discourse context. This means that expressions of the demonstrative reference refer to an entity by describing its relative position within the discourse situation.

In this respect, Halliday and Hasan (1976) classify the demonstrative reference into the following two categories. The first one is the adverbial demonstrative reference which refers to the location where or when the event takes place. The words that belong to this category are here, there, now and then. Novianti explains that "the circumstantial (adverbial) demonstratives like here, there, now and then, refer to the location of a process in space or time" (2009: 29). The second category is the nominal demonstrative reference which refers to a place, person or an object where something does exist. The words that belong to this category are this, these, that, those and the.

\subsection{Literal Translation}

Literal translation is a procedure that involves the conveyance of denotative meaning of phrases and sentences in a text from one language to another. In other words, it is a rendering that preserves the surface aspects of the messages, both semantically and syntactically, adhering closely to the source text mode of the expression.

It should be noted that literal translation is the procedure that does not follow the source language grammar as it is the case with word-for-word translation. It is the procedure that adopts the target language grammar.

\subsection{Formal Equivalence}

Formal equivalence derives its name from the fact that it focuses primarily on the form of the original. It is a procedure that seeks to capture the form of the source language expression. In other words, it focuses primarily on the form of the original. As Nida (1964) puts it, "it ... focuses attention on the message itself, in both form and content" (p. 159).

\section{Research Approach}

In this research, descriptive analytical study has been employed. This method is used in order to discover, identify, analyze and describe the sentences of implicit meanings in the novel, "Harry Potter and the Prisoner of Azkaban," and the methods of translating the implicit meaning in the novel.

In this regard, Franenkle and Wallen (1993) argue that the descriptive method is "a method to explain, analyze and classify something through various techniques, surveys, interviews, questionnaires, and tests" (p. 23). The data collected will be compared and analyzed based on the theories outlined in the previous section.

To this end, the data of the source novel, "Harry Potter and the Prisoner of Azkaban," by J. K. Rowling (2010), as well as its Arabic version, translated by Ahmad Hasan Mohammed, will be described. Eight specific examples taken from that novel and its translated version will be used to conduct the present study. In each of these examples, two versions will be used. The first one, called in this study as Data a, has been taken exactly as it appeared in the original novel by Rowling. As for the second version, called Data b, it has been taken exactly as 
it appeared in the translated edition into Arabic.

The translated examples have been written in accordance with the transliteration symbols for Arabic vowels and some consonants specified by the Association of Professors of English and Translation at Arab Universities, [APETAU], (1997).

\section{Results}

The translation of the English implicit demonstrative reference into Arabic can be done implicitly or explicitly by paying attention to the reference. An implicit translation can be achieved if the entailments of the demonstrative reference are clear and understandable without causing an ambiguity and without sacrificing the unity of meaning. To illustrate this point, the following eight examples of translating the demonstrative reference will be considered.

Data 1. a

"Boggarts like dark, enclosed spaces. This one moved yesterday afternoon and I asked" (p. 145).

Data $1 . \mathrm{b}$

Pina Boggarts yuhibu lRama:kina lmughlaqa... walaqad taharaka huna: bil?amsi watalaba... (p. 139)

The demonstrative pronoun "this" in the example, numbered Data 1. a, functions as a modifier to the head noun "one". The word "this," which refers anaphorically to something the speaker himself has said, is limited to "one" Boggarts mentioned in the previous sentence. Here the translator has opted for translating the demonstrative "this" implicitly by deleting the demonstrative pronoun. This translation is clear because the referent is mentioned in the previous sentence.

\section{Data 2. a}

"I would like to speak to Harry and Hermione alone," said Dumbledore abruptly... This cannot wait, said Dumbledore. I must insist" (p. 421).

Data 2.b

Pana: Puri:du tahadutha $\mathrm{ma}^{\mathrm{c}}$ Harry wa Hermione bimufradina:. Qa:la Dumbledore: ha:dha: la: yumkin taPji:lahu... Pinani: Pusiru 'ala: dha:lik. (p. 388)

The demonstrative pronoun "this" regularly refers anaphorically to something that has been said before; a speaker uses "this" to refer to something he himself has said. Therefore, the demonstrative "this," mentioned in Data 2. a, refers to the speaker's desire of speaking to Harry and Hermione alone. In Arabic the translator opted for keeping the demonstrative pronoun implicit as (ha:dha:). This translation is clear and captured in the target language because the referent is mentioned in the previous sentence, so it would be redundant to repeat the referent explicitly.

Data 3. a

"I need you to sign the Permission form, said Harry in a rush. And why should I do that? Sneered Uncle Vernon" (p. 27).

Data 3. b

Paja:ba Harry fi: ${ }^{c}$ ajala: Puri:du Pan twaqi ${ }^{\mathrm{c} a}$ li: tassi:h ilmwa:faqa, farada ${ }^{\mathrm{c}}$ alayhi bihida: walima:dha: yajibu calaya Pan Paf ala dha:lik? (p. 23)

There is an implicitness of the demonstrative pronoun "that" which is mentioned in Data 3. a. The demonstrative pronoun regularly refers anaphorically to something that has been said before. The demonstrative pronoun is used to refer to something said by the speaker's interlocutor. Here, the translator opted for translating the referent implicitly as (dha:lik). Therefore, this translation is clear and captured in the target language because the referent in question "the signing of the permission form" is mentioned in the previous sentence. 
Data 4. a

"But he was clever enough to Escape from Azkaban, and that's supposed to be impossible" (p.74).

Data 4. b

wala:kinahu ka:n ma:hiran lidarajat ilhuru:bi min Azkaban, wahuwa ma: yuftaradu Pan yaku:na mustahi:lan. (p. 71)

The demonstrative pronoun "that" which is stated in the example, numbered Data 4. a, has an implied referent. It refers to the incident of escaping from Azkaban, as stated in the previous clause. In the translation, the reference might be made explicit or left implicit. The translator opted for keeping the referent implicit in the form of personal pronoun (wahuwa).

Data 5. a

"I'm your godfather. Yeah, I knew that, said Harry." (p. 408).

Data $5 . \mathrm{b}$

Pinani: Pabu:ka ru:hyi Paja:ba Harry: na ${ }^{c} a m$. Laqad ${ }^{c}$ araftu dha:lik. (p. 376)

The example, numbered Data 5. a, has a demonstrative pronoun "that" which anaphorically refers to the entire clause "I'm your godfather." In such cases, "that" usually refers to something that has been said before, and it is used to refer to something said by the speaker's interlocutor. The translator here opted for keeping the demonstrative pronoun implicit as (dha:lik). This translation is clear because the referent in question is mentioned in the previous sentence. Therefore, the meaning is captured in the target language.

Data 6. a

"Professor McGonagall opened the classroom door at that moment, which" (p. 162).

Data 6. b

min husini lhaTHi Pana liustadha McGonagall fatahat ba:b ilfasli fi: tilka alahtHHa. (p. 156)

The example, numbered Data 6. a, has a demonstrative pronoun "that" which refers cataphorically to the referent "moment." The demonstrative "that" is associated with a past-time referent. Here the translator opted for translating it implicitly as (tilka).

Data 7. a

"They're horrible things, those Dementors..." (p. 108).

Data $7 . b$

wa huna: ${ }^{c}$ a:da George yaqu:l: ?na: Pydan lam ?kun sa ${ }^{c} i$ :dan bihim... Pinahum Pashya:Pa faTHi:catun ha:?ula:?i lharas. (p. 104)

The example, numbered Data 7. a, has a demonstrative reference "those" which refers cataphorically to the count plural "dementors." In this case, "those" with a following noun refers just to the presupposed item "dementors." In translation, the translator kept the demonstrative adjective implicit. But if the entailment of reference is not clear, the translator has to opt for translating the implicit demonstrative reference explicitly. This example is considered to show the point.

Data 8. a

"Neville's lips moved, but no noise came out. Didn't catch that, Neville, sorry" (p. 147). 
Data $8 . \mathrm{b}$

Taharakat shifata Neville du:na Pan yasdura ${ }^{\mathbf{c}}$ anhu Payu sawt, faqa:la lmu ${ }^{\mathbf{c}}$ alim: ${ }^{\mathbf{c}}$ afwan... Pana: lam Pasma $^{\mathbf{c}}$ ma: qult. (p. 141)

Data 8. a example has the demonstrative reference "that" which refers to the speech made by Neville in the previous sentence. In the translation process, the reference might be made explicit or left implicit. When the choice is to be made implicit, the sentence would be (Pana: lam Pasma ${ }^{c}$ ma: dha:lik). Here, the translator chose the reference to be made explicit, so translating the phrase as (Pana: lam Pasma ${ }^{\mathrm{c}}$ ma: qult) makes the sentence clearer and the meaning is easily understood.

\section{Discussion}

The study conducted has shown that most of the English implicit demonstrative reference data have been translated into Arabic implicitly. The translator opted for translating data 1, 2, 3, 4, 5, 6 and 7 implicitly because the demonstrative pronouns in these examples refer anaphorically to something that has been said before. Thus, the translation is clear and captured in the target language because the referents are mentioned in the previous sentences, if the translator opted for explicit translation, it would be redundant to repeat the referents explicitly. Since seven data out of eight are translated implicitly, this conclusion validates hypothesis number one.

The second research hypothesis is concerned with selecting a procedure of translation and a type of equivalence that will be considered favorable options in rendering implicit demonstrative reference. After examining the above-mentioned examples, which were taken randomly from Rowling's novel (2010), the study has shown that in most cases the translator opted for keeping the implicit meaning. Thus, literal translation present itself as a valid option and as a result formal equivalence is preserved.

It should be noted that formal equivalence is the type and literal translation is the method, which have been adopted to accomplish the goal of keeping the same cohesive devices in both, the source language and the target language. This would validate hypothesis number two.

\section{Conclusion}

The conclusions of the study are as follows:

1) An implicit translation can be achieved if the entailments of demonstrative references are clear and understandable without causing an ambiguity and without sacrificing the unity of meaning, and if the target language has a grammatical system which allows that.

2) An implicit demonstrative reference should be translated explicitly if it causes ambiguity or vagueness in the target language.

\section{Recommendations}

In light of the results of the study, the researchers offer the following recommendations:

1) This study can be a useful guidance in having a field research about measuring the tendency of translating implicit meaning, whether the tendency lies in translating it explicitly or implicitly.

2) More attention should be paid to the topic of implicit meaning and types of implicit meaning by allocating parts of a textbook to throw light on the problem, and presenting ways of translating those types.

\section{References}

APETAU (Association of Professors of English and Translation at Arab Universities). (1997). Retrieved from Www.apetau.org

Franenkle, J. R., \& Wallen, N. E. (1990). How to design and evaluate research in education. New York: McGraw-Hill.

Halliday, M., \& Hasan, R. (1976). Cohesion in English. London \& New York: Longman.

Larson, M. L. (1984). Meaning based translation: A guide to cross language equivalent. Boston: University Press of America.

Larson, M. L. (1998). Meaning based translation: A guide to cross language equivalent (2nd ed.). New York: University Press of America.

Nida, E. A. (1964). Towards a science of translation. Leiden: E. J. Brill. 
Novianti, R. (2009). The analysis of translating demonstrative reference in J. K. Rowling's novel Harry Potter and the Chamber of Secrets into Indonesian version (Unpublished thesis).

Rowling, J. K. (2010). Harry Potter and the prisoner of Azkaban. London: Bloomsbury Publishing.

Rowling, J. K. (2010). Harry Potter and the prisoner of Azkaban (A. H. Mohammed, Trans.). London: Bloomsbury Publishing.

\section{Copyrights}

Copyright for this article is retained by the author(s), with first publication rights granted to the journal.

This is an open-access article distributed under the terms and conditions of the Creative Commons Attribution license (http://creativecommons.org/licenses/by/4.0/). 